\title{
Analysis of Thickness Distribution in Cup Produced by Rubber Pad Forming
}

\author{
Karem M. Younis ${ }^{1}$, Adnan I. Aljarjary ${ }^{2}$, Jalil J. Shukur*3 \\ 1,2,3 Department of Production Engineering and Metallurgy, University of Technology. \\ *corresponding author: email address: Jaliluot@gmail.com
}

\begin{abstract}
In many manufacturing fields such as the aeroplanes and automobiles industries, the control of the thinning variations in produced parts is a major point to investigate since good thickness distribution mean the reliability of these products. In this framework, several experimental and numerical modeling tests have been developed for the purpose of studying phenomenon of thinning during rubber pad forming process. The low carbon steel (AISI 1080) has been used as the blank material. Three forming block shapes had been used (flat, hemispherical and complex), rubber pad with three different hardness (50, 60 and 70 Shore A) also the rubber pad thickness have (40, 60 and 80 $\mathrm{mm})$. The results have showed that improvement in thickness distribution occurred with decrease in rubber hardness and thickness distribution is various from one deformation style to other.
\end{abstract}

Keywords: Rubber pad forming; Thickness distribution; Numerical simulations ; Thinning

Paper history: (Received:21-5-2019; Accepted:24-92019)

\section{Introduction}

In sheet metal forming operations, the geometry of blank sheet follows the geometry of die cavity. Flexible forming rises in recent years to push sheet metal to deform using flexible medium such as rubber, hydraulic or pressurized air [1]. The flexible die forming is employed to acquire uniform forming pressure distribution on all formed workpiece sides as it is formed to geometry of forming block [2,3],the uniform forming of sheet leads to perform good thickness distribution thereby overcoming thinning which occurs in conventional sheet metal forming $[4,5]$.

Abbas et al. [6] have experimentally investigated the rubber pad forming operation of sheet metal. Some forming variables like blank thickness, kind of material, rubber pad thickness and the geometry of the tools are studied. The results obvious that the forming force is inversely proportional to sheet for same forming travel. In addition, it has found for increasing the thickness of pad improved the necessary forming energy.

Elyasi et al. [7] have introduced the influences of concave and convex punch and rubber features on rubber pad sheet metal forming process. In their paper, the blank material has steel 316 having thickness of $0.1 \mathrm{~mm}$ and a rubber pad with a of 85 Shore A hardness was employed to produced final products. The results have showed that, for a similar subjected forming load, the convex former showed lower filling ability than the concave former. Furthermore, when increasing forming force, no considerable increase in filling ability happens with both formers, but increasing the forming force leads to tear in rubber pad. The effect of sheet thickness and type on the rubber pad forming operation introduced in the research of Niknejd and Karami [8] their discoveries offered that the radius of bending for the produced parts increase when width cavity of forming block improved, so the forming force decreases. The results also showed that the forming load increases with increases sheet initial thickness. Koubaa et al [9] have estimated the ability of rubber pad forming, by comparison tube bulging using rubber and hydroforming bulging. In order to compare, a numerical simulation model has generated for each forming operation and explained. A notable result has been utilizing rubber as a pressure-carrying medium has suggested to improving distribution of thickness and enhancing formability.

The hardness of rubber becomes prominent effect in performing the required product shape, Tandogan and Eyercioglu [10] have studied the effect of Polyurethane hardness on forming of dome shaped parts, Polyurethane materials with 60 and 80 shore A, Aluminum sheet ( $\mathrm{Al}$ 1100 ) with $0.5 \mathrm{~mm}$ thickness has used as blank material in experimental work and numerical modeling. The results have showed that harder polyurethane is proper to draw the blank in the desired shape. Though, more forming load is needed compared to softer polyurethane. The results also revealed that the rubber pad forming is very applicable for forming parts without excessive thinning. Forming of some complex grooves on bipolar plate is one of the most important challenges facing sheet metal forming operations W. Hongyu et al. [11] investigated the rubber pad forming of some complicated channels by studying the influence of geometrical variables in experimental and numerical simulation. The results have showed that channels produced by convex punch that have better than these produced by concave punch, the propensity of the results about stress and shapes can be adopted to manufacture a better punch in rubber pad forming.

\section{Theoriticaal Considerations}

\subsection{Determining the blank size for different parts}

The starting workpiece is a circular blank of sheet metrial. The dimensions and geometry of the workpiece are important for consumption of metal, for the design of the drawing tooling and the cost-effectiveness of the process. 
While calculating the blank dimensions, it is supposed that the blank thickness remains constant during the forming process. For parts shown in Figure(1) the following equations are used to determine blank diameter (D) for flat ,hemispherical and complex cups[6]:

$$
\begin{aligned}
& D=\sqrt{d^{2}+4 \cdot d \cdot h+2 \cdot f \cdot\left(d+d_{f}\right)} \\
& D=\sqrt{d^{2}+4 \cdot\left[h_{1}^{2}+d \cdot h_{2}+0 \cdot 5\left(d+d_{f}\right)\right.} \\
& D=\sqrt{d_{f}^{2}+4 \cdot\left(d_{1} \cdot h_{1}+d \cdot h_{2}\right)}
\end{aligned}
$$

Where:

$\mathrm{d}=$ diameter of cup.

$\mathrm{d}_{\mathrm{f}}=$ diameter at flange

$\mathrm{h}, \mathrm{h}_{1}, \mathrm{~h}_{2}=$ Heights of cup.

\subsection{Thinning and Thickening regions along cup wall}

The development in conventional and nonconventional sheet metal forming processes seeks to achieve the uniformity of final thickness distribution and reduce sheet thinning as much as possible since it leads to failure at a particular region especially at former block profile (FBP) regions where severe stretching and bending occur. The formed parts not only suffer from thinning in some regions but also thickening in other regions such as flange regions.

Greatest thinning probably happen on the sidewall, near the cup bottom. An acceptable produced cup may have up to $25 \%$ change in thickness in some portions.

The starting thickness of sheet metal (to) and the formed thickness of part at the location of interest $\left(\boldsymbol{t}_{\boldsymbol{f}}\right)$. The percent thinning is calculated as shown in the equation below.

$$
\text { Thinning percentage }=\frac{t_{0}-t_{f}}{t_{0}} * 100
$$

\section{1 characteristics of sheet material}

Low carbon steel is selected to be the material of the workpiece to be drawn in rubber pad sheet metal forming (RPSMF), this choice due to it possess good drawing bility, that offers a good working window in parry the main two sheet metal forming failure wrinkling and tearing. This material is taken as a sheet with thickness $\left(t_{0}=0.5 \mathrm{~mm}\right)$, the reason in choice this thickness due to the problems in the drawing of sheet arises with decreasing thickness gauge, subsequently by using RPSMF trying to eliminate this problem. Identical round workpiece of $40 \mathrm{~mm}$ radius have cut out from the metal. A chemical composition test has carried out by using a spectrometer to examine the manufacture certificate of metal as shown in Table (1).

Table 1: Chemical composition of low carbon steel

\begin{tabular}{ccccccccc}
\hline \hline Component & $\mathrm{C}$ & $\mathrm{Si}$ & $\mathrm{Mn}$ & $\mathrm{S}$ & $\mathrm{P}$ & $\mathrm{Cr}$ & $\mathrm{Ni}$ & $\mathrm{Fe}$ \\
\hline $\begin{array}{c}\text { Percentage } \\
\%\end{array}$ & 0.093 & 0.018 & 0.41 & 0.024 & 0.023 & 0.028 & 0.022 & Rest \\
\hline
\end{tabular}

In order to determine of mechanical properties of sheet material, the tensile test has carried out to determine the mechanical properties. Figure(2) demonstrated the stressstrain curve of sheet has used in this research. while Table (2) presented the mechanical properties that obtained from tensile test of sheet material, these will be used to define blank material in numerical simulation work.

Table 2: Mechanical properties of blank material.

\begin{tabular}{cccc}
\hline \hline $\begin{array}{c}\text { Material } \\
\text { property }\end{array}$ & $\begin{array}{c}\text { Modulus of } \\
\text { elasticity }(\mathrm{E})\end{array}$ & $\begin{array}{c}\text { Poisson's } \\
\text { ratio }(v)\end{array}$ & $\begin{array}{c}\text { Yield } \\
\text { stress }\left(\sigma_{\mathrm{v}}\right)\end{array}$ \\
\hline Magnitude & $200 \mathrm{GPa}$ & 0.3 & $2 \imath$ \\
\hline
\end{tabular}

\section{Experimental work}

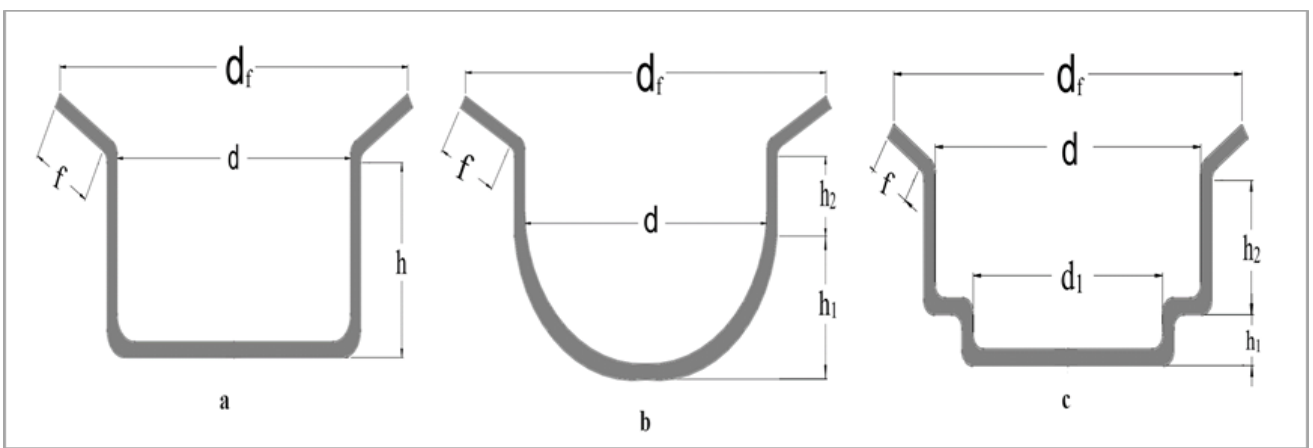

Figure (1). Different cup shapes design a. flat ,b. hemispherical and c. complex cup 


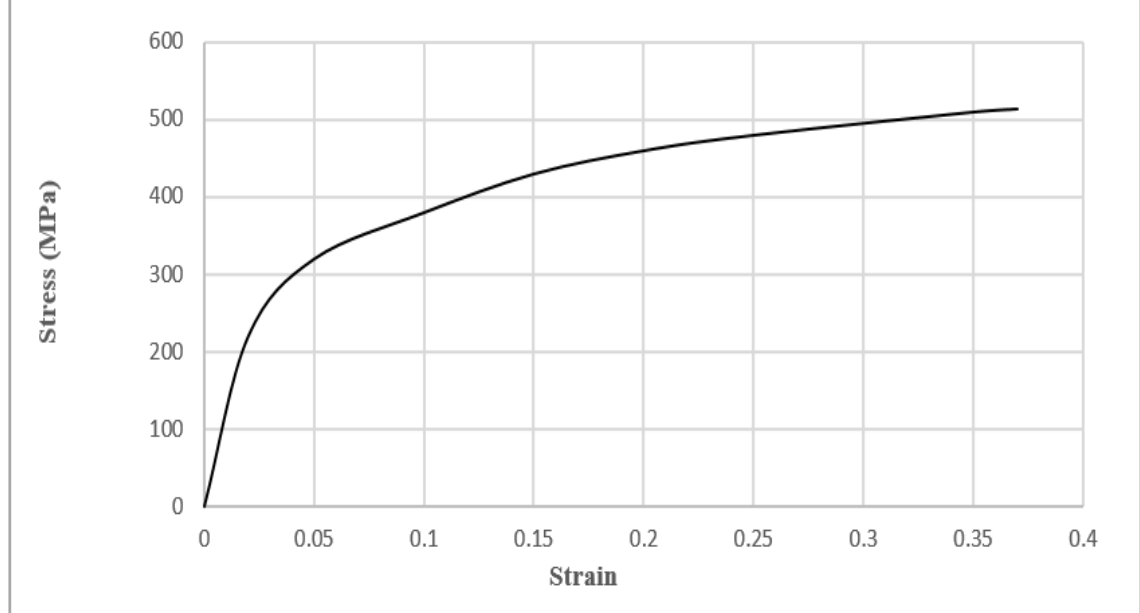

Figure (2). Stress-strain curve for low carbon steel (AISI 1080).

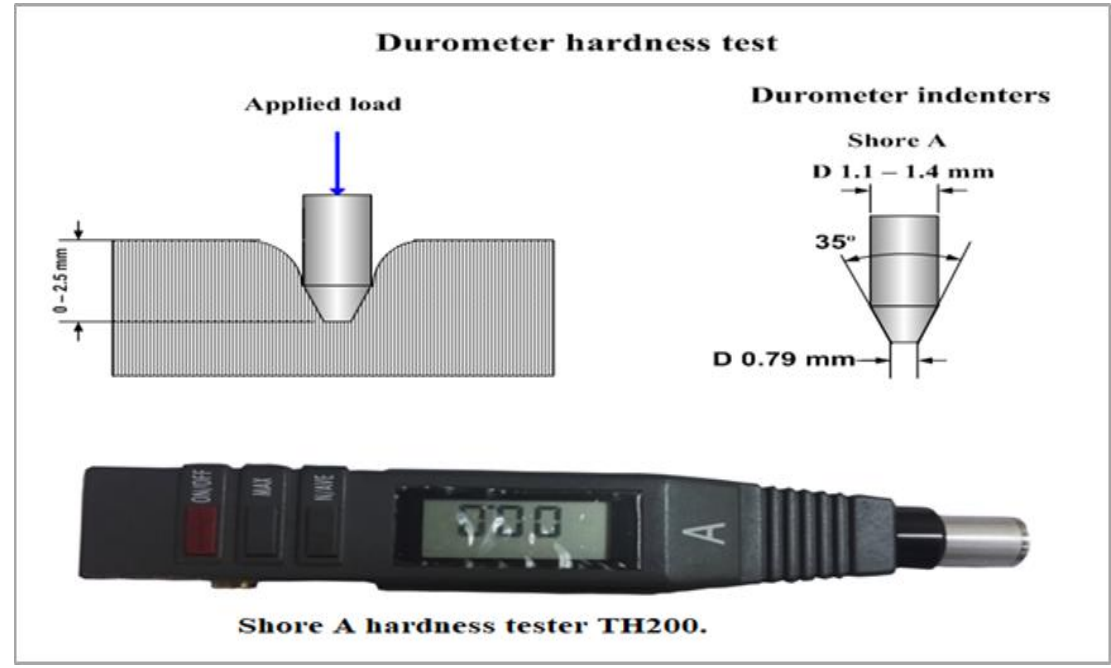

Figure (3).Durometer test details.

\subsection{Characteristics of rubber material}

A polyurethane has selected to be the material for rubber pad, the selection of polyurethane rubber because of it is obtainable in wide range of shore hardness as well as it can be prepared during a chemical reaction of a diisocyanate and a polyol to attain the necessary rubber pad with preferred dimensions and mechanical properties. To inspect the hardness of rubber, the Shore test was carried out. The test is made with a measuring device called durometer as shown in Figure(3).Three rubber types have been used with different hardness $(50,60$ and 70$)$ Shore A. The hardness is used in order to find Mooney Rivlin Constant (G,E,C01 and C10)that used to define rubber material in numerical modelling as will be discussed later.

\subsection{Equipment and tools}

Sheet metal forming drawing die was design and manufactured, to meet the requirement of planned experimental tests some parts of the die were interchangeable. The following tool has been prepared and manufactured:
1. Three former blocks with different shapes :flat former block (FFB), Hemispherical former block (HFB) and complex former block (CFB). As illustrated in Figure (4).

2. Rubber metallic container. As illustrated in Figure (5).

3. Drawing die auxiliaries include ( upper plate, a lower plate, guides, spring, and bolt). As illustrated Figure (6).

The cross sectional and isometric views of RPSMF die was used in experimental work was demonstrated in Figure (6).

\section{Numerical simulation}

Finite element analysis (FEA) is adopted ANASYS Workbench (18.2) to perform the numerical modeling of RPSMF process, Two material models has used to define of material used :

1- Multilinear isotropic hardening assumption is used to define material properties of workpiece (sheet metal). Figure 2 presents the true stress strain curve, the elastic region is define by elastic constant as illustrates in table 2. 
2- Mooney-Rivlin model is used to define material properties of rubber pad material

Table 3. Mooney-Rivlin constant based on Shore hardness [5].

\begin{tabular}{ccccc}
\hline $\begin{array}{c}\text { Shore } \\
\text { A }\end{array}$ & G & E & C10 & C01 \\
\hline 50 & 0.755 & 2.397 & 0.302 & 0.076 \\
60 & 1.185 & 4.268 & 0.474 & 0.118 \\
70 & 1.839 & 7.289 & 0.736 & 0.184 \\
\hline
\end{tabular}

The numerical modeling work in this study utilize twodimensional axial symmetry as demonstrated in Figure (7) model geometry accompanied by applying of appropriate boundary conditions in order to represent a complete physical model as described in the following:

1. Define axis of symmetry at left edge of former block, blank and rubber pad.

2. Fixed support at the lower edge of rubber pad to present die lower plate.

3. Fixed support at edge above to represent pressure plate that restrained the vertical movement of sheet and rubber at this region.

4. Frictionless support at rubber pad right edge to restrict rubber move in horizontal direction while it free to move in vertical direction.

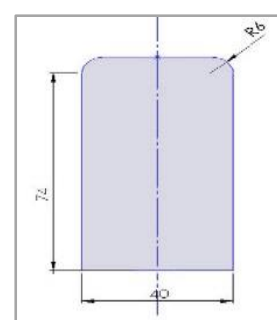

a
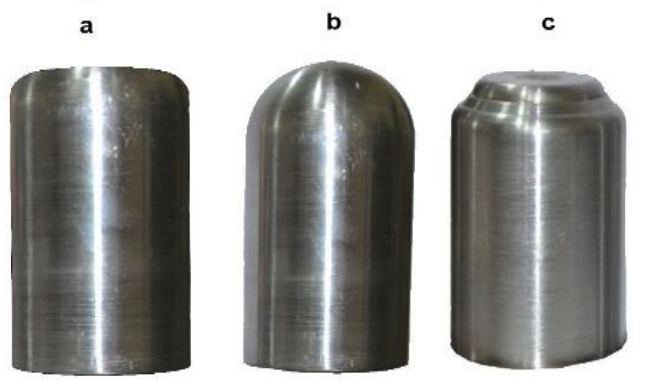

Figure (4). Cross sectional view and manufactured a. Flat , b. Hemispherical and c. Complex
5. Applying velocity at former block upper edge subrogate press head movement.

\section{Results and discussion}

The influencing of rubber hardness and thickness is to discuss, by studying the SRP as presented in figures (8), (9) and (10). Naturally, the results vary from one former block to another based not only affecting parameters but also on deformation styles of this former block.

\subsection{Flat Former Block}

The most important is thickness reduction at curvature region near cup especially at former block profile (FBP) region, where the maximum thinning is expected to occur in it. On the other hand, the flange region suffers from thickening.

Figure (8) demonstrated the effect of rubber pad hardness (RPH) and rubber pad thickness (RPT) on cup wall thickness distribution. The observed correlation between wall thickness and rubber pad hardness is with increase hardness the thinning at FBP region increase and thickening at flange decrease, this effect appears with all rubber pad thickness, the reason behind increases in stretching in

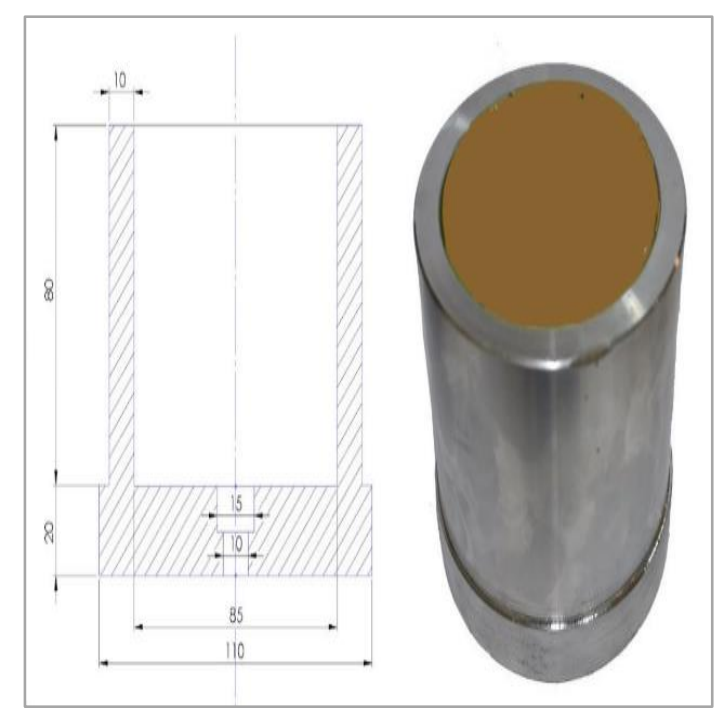

Figure (5). Cross sectional view and manufactured rubber container. 


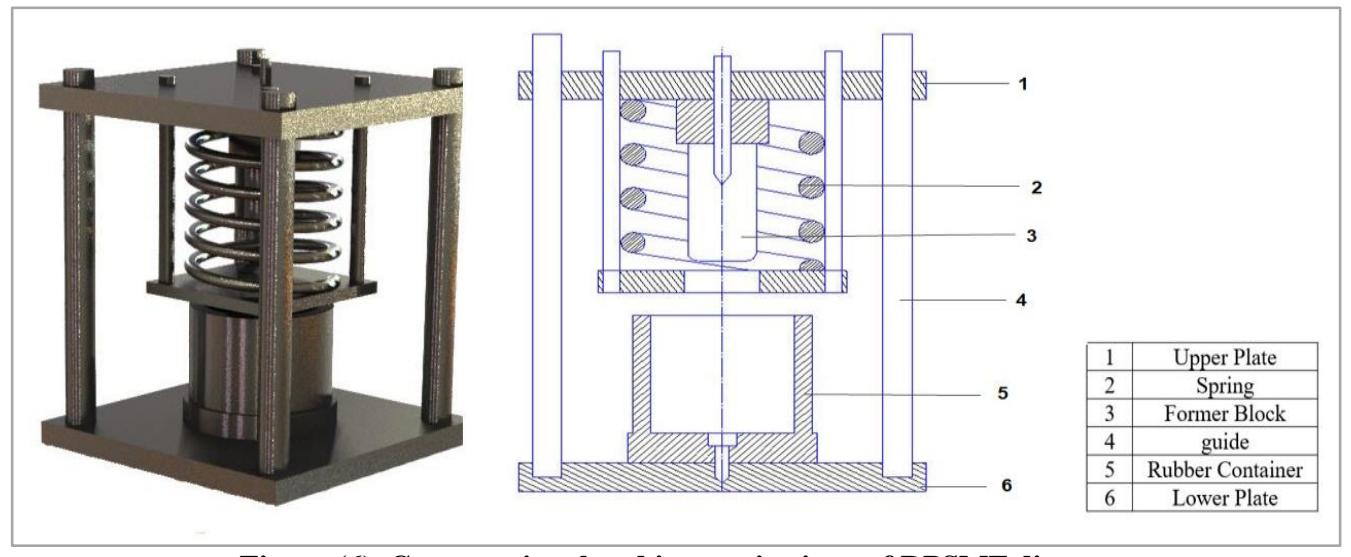

Figure (6). Cross sectional and isometric views of RPSMF die.

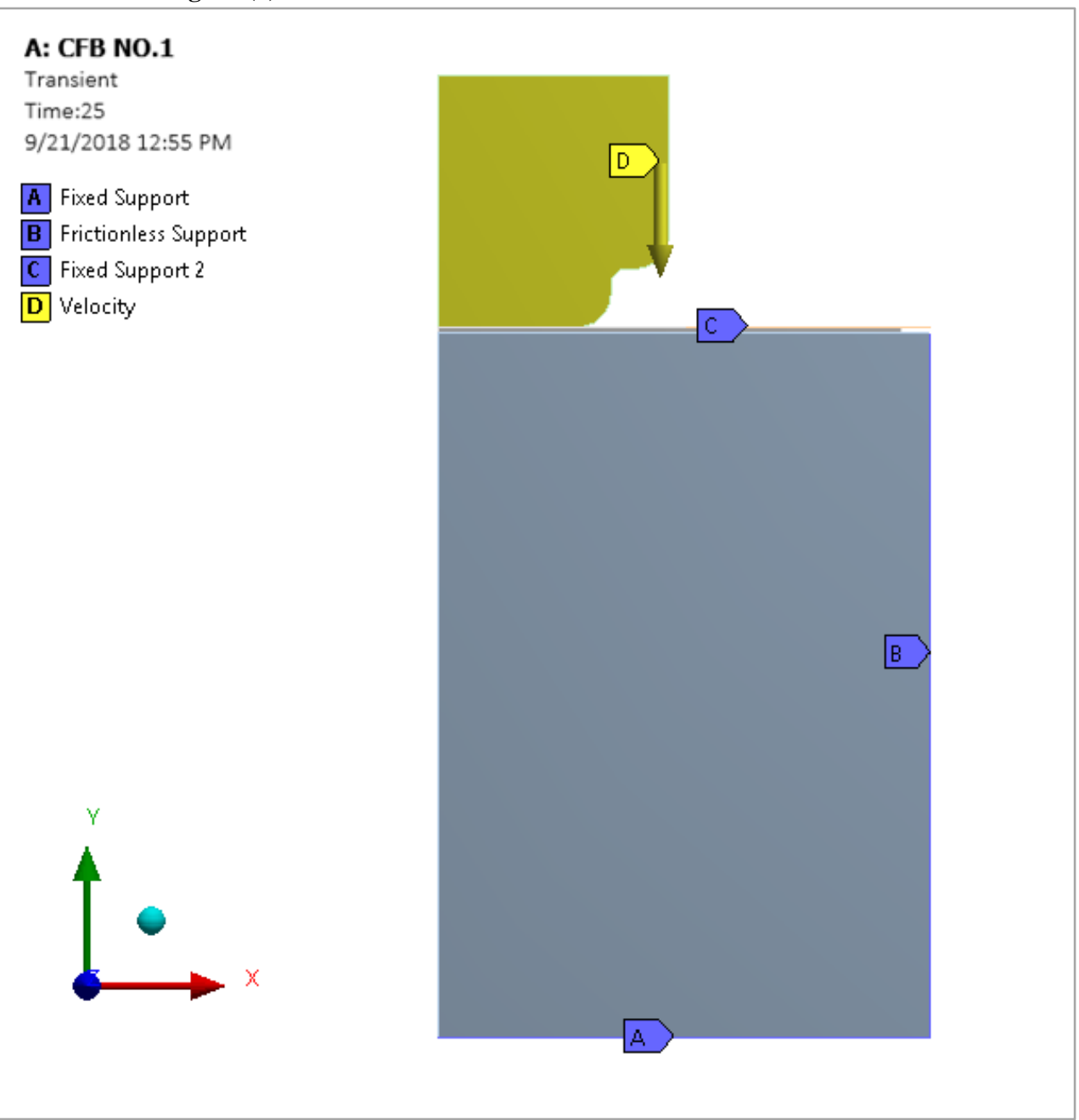

Figure (7).Constraint applied on complex former model as an example.

cup wall with harder rubber which leads to a decrease in wall thickness especially in FBP region where the stretching accompanied by bending on former block profile radius. But regarding thickening, the reason is hoop strain at flange rim increases with softer rubber so that the thickening at this region increase.

But regarding the influence of rubber pad thickness, the effect has inverse, as the thinning at the FBP region decrease and thickening at flange region increase with increase rubber pad thickness.
The maximum thinning percentage has $27.2 \%$ occurred when RPH of 70 Shore A and RPT of $40 \mathrm{~mm}$. The minimum thinning percentage was $12 \%$ occurred when RPH of 50 Shore A and RPT of $80 \mathrm{~mm}$. The maximum thickening percentages were $12.8 \%$ appeared at $\mathrm{RPH}$ of 50 shore A and RPT of $80 \mathrm{~mm}$. The minimum thickening percentage was $2 \%$ appeared at RPH of 70 shore A and RPT of $40 \mathrm{~mm}$. 

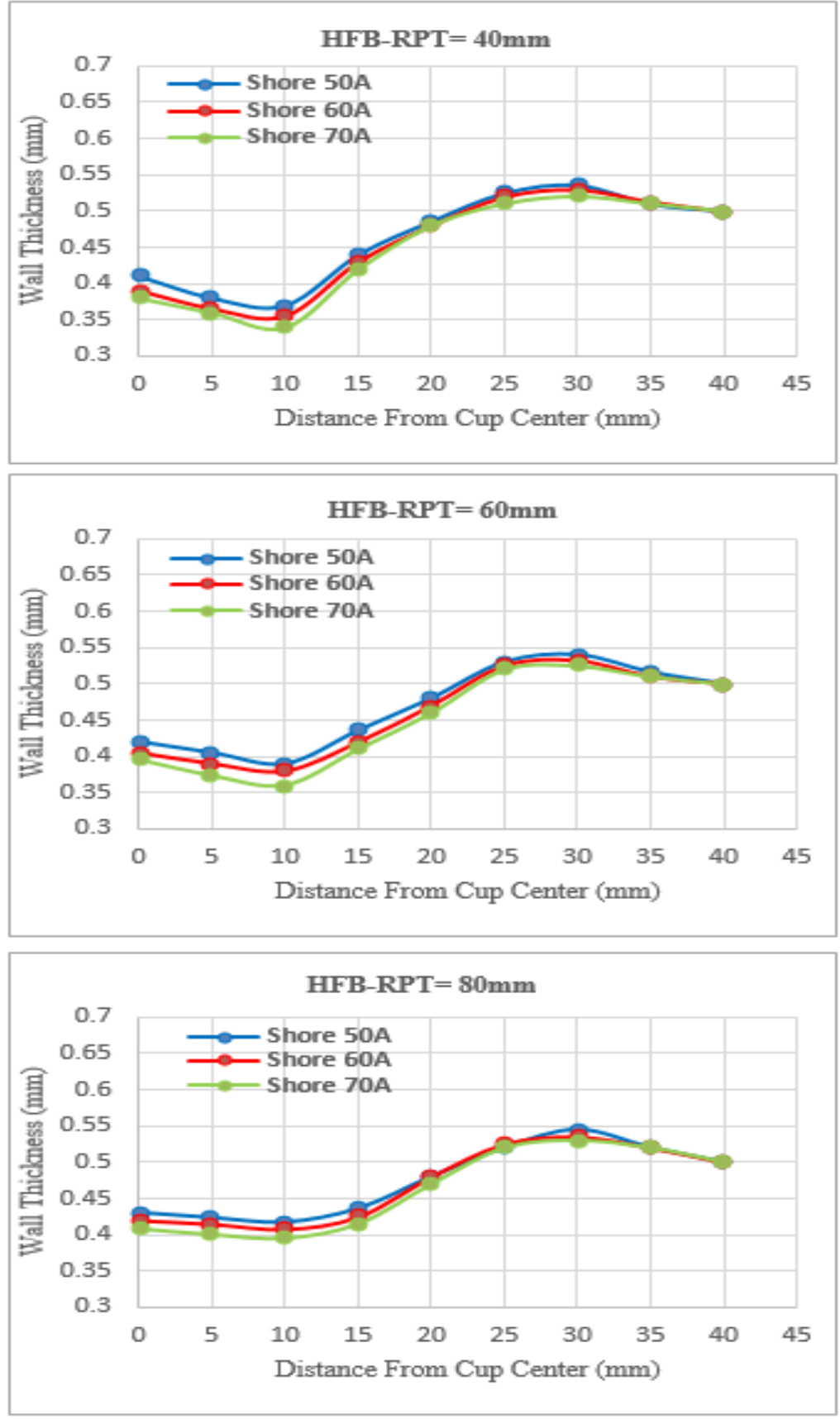

Figure (9). Effect of rubber hardness on thickness distribution for hemispherical former block

\subsection{Hemispherical Former Block}

The only thing that distinguishes HFB from FFB is extended of profile radius to include all cup bottom. This geometrical feature alters thickness distribution which makes all cup bottom is thinning expected region as presented in Figure (9). Although the difference in curve shapes than it has FFB, The effect of rubber hardness and thickness remained the same. The maximum thinning percentage has $32 \%$ occurred when RPH of 70 Shore A and RPT of $40 \mathrm{~mm}$. The minimum thinning percentage has
$17.4 \%$ occurred when RPH of 50 Shore A and RPT of 80 $\mathrm{mm}$. The maximum thickening percentages have $9 \%$ appeared at RPH of 50 shore A and RPT of $80 \mathrm{~mm}$. The minimum thickening percentage has $4 \%$ appeared at RPH of 70 shore A and RPT of $40 \mathrm{~mm}$.

The maximum thinning has appeared at $10 \mathrm{~mm}$ distance from center for HFB, whilst it have appeared at 20 $\mathrm{mm}$ for FFB. On the other hand, the maximum thickening appeared at $30 \mathrm{~mm}$ for HFB and at $40 \mathrm{~mm}$ for FFB. 

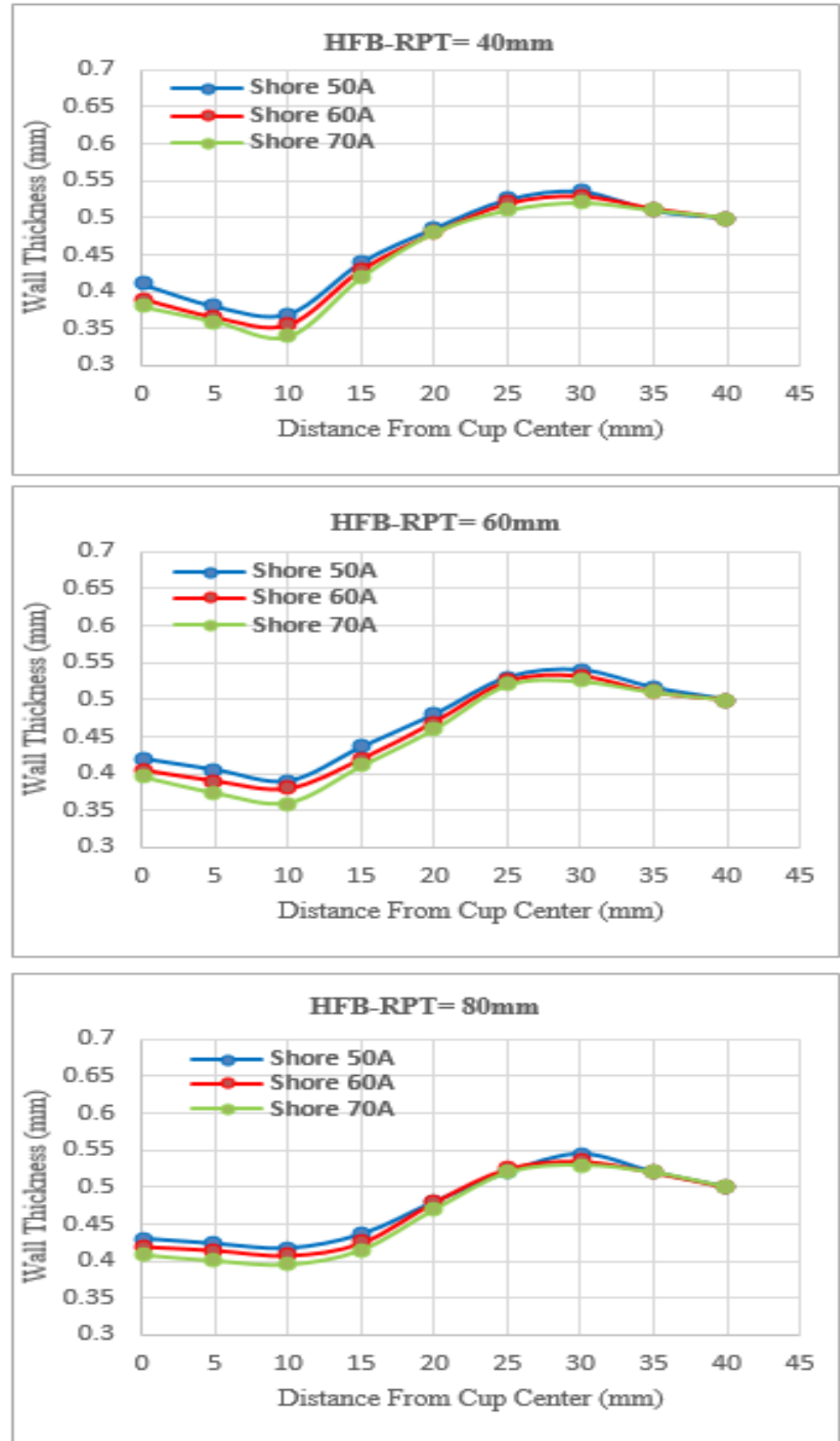

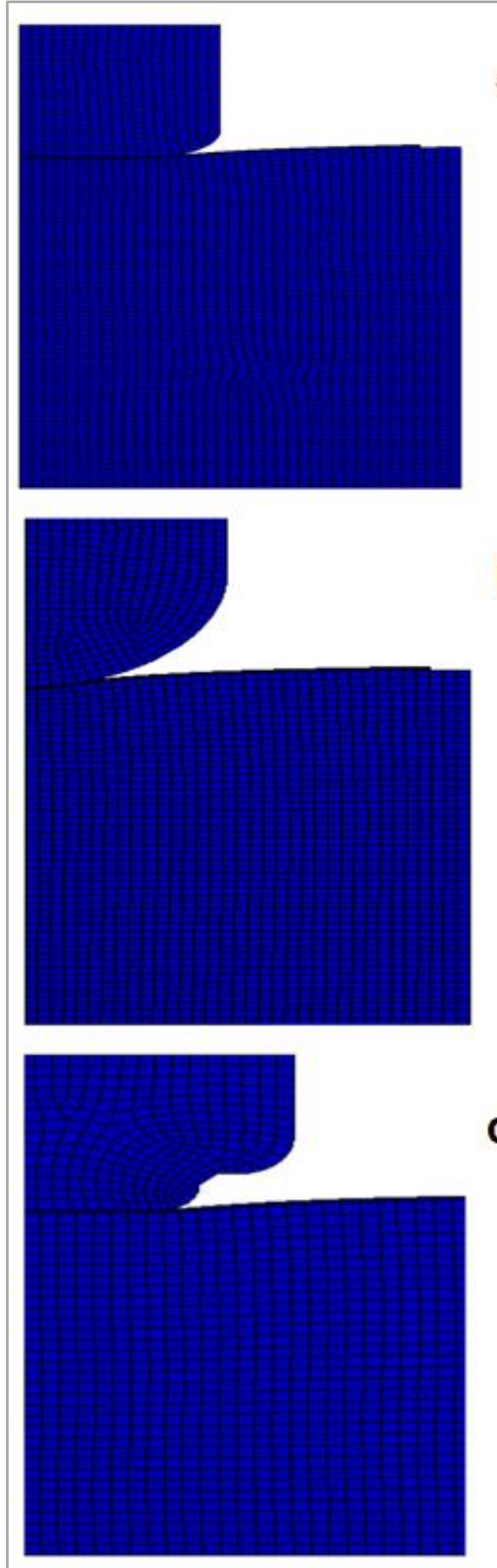

C

\subsection{Complex Former Block}

Opposite of what has in FFB and HFB curves, the CFB comprise two thinning regions, as a result of two profile radius in complex former. The maximum thinning occurs in the nearest profile to cup center as demonstrated in figure (10). The maximum thinning percentage has $36 \%$ occurred when RPH of 70 Shore A and RPT of $40 \mathrm{~mm}$. The minimum thinning percentage has $17 \%$ occurred when $\mathrm{RPH}$ of 50 Shore A and RPT of $80 \mathrm{~mm}$. The a

b
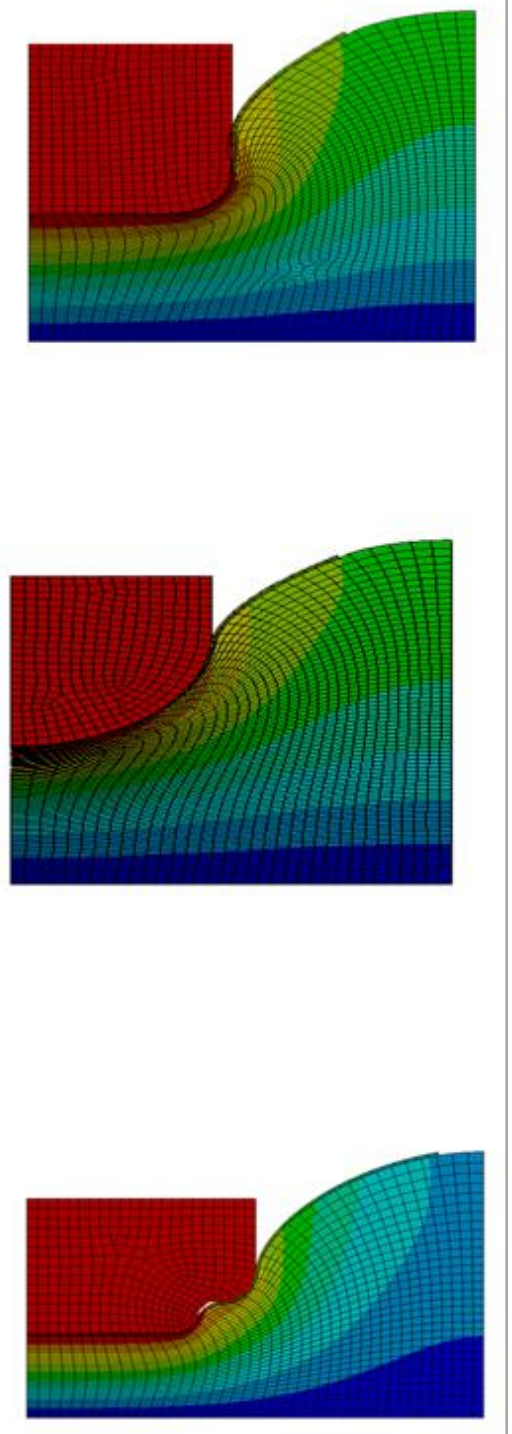

Maximum thickening percentages were $7 \%$ appeared at RPH of 50 shore A and RPT of $80 \mathrm{~mm}$. The minimum thickening percentage has $2 \%$ appeared at RPH of 70 shore A and RPT of $40 \mathrm{~mm}$. The results also approved by numerical simulation for different former blocks.

The initial and final step of numerical models have demonstrated in figure 11.The completely drawn cups of experimental work were shown in figure 12. 

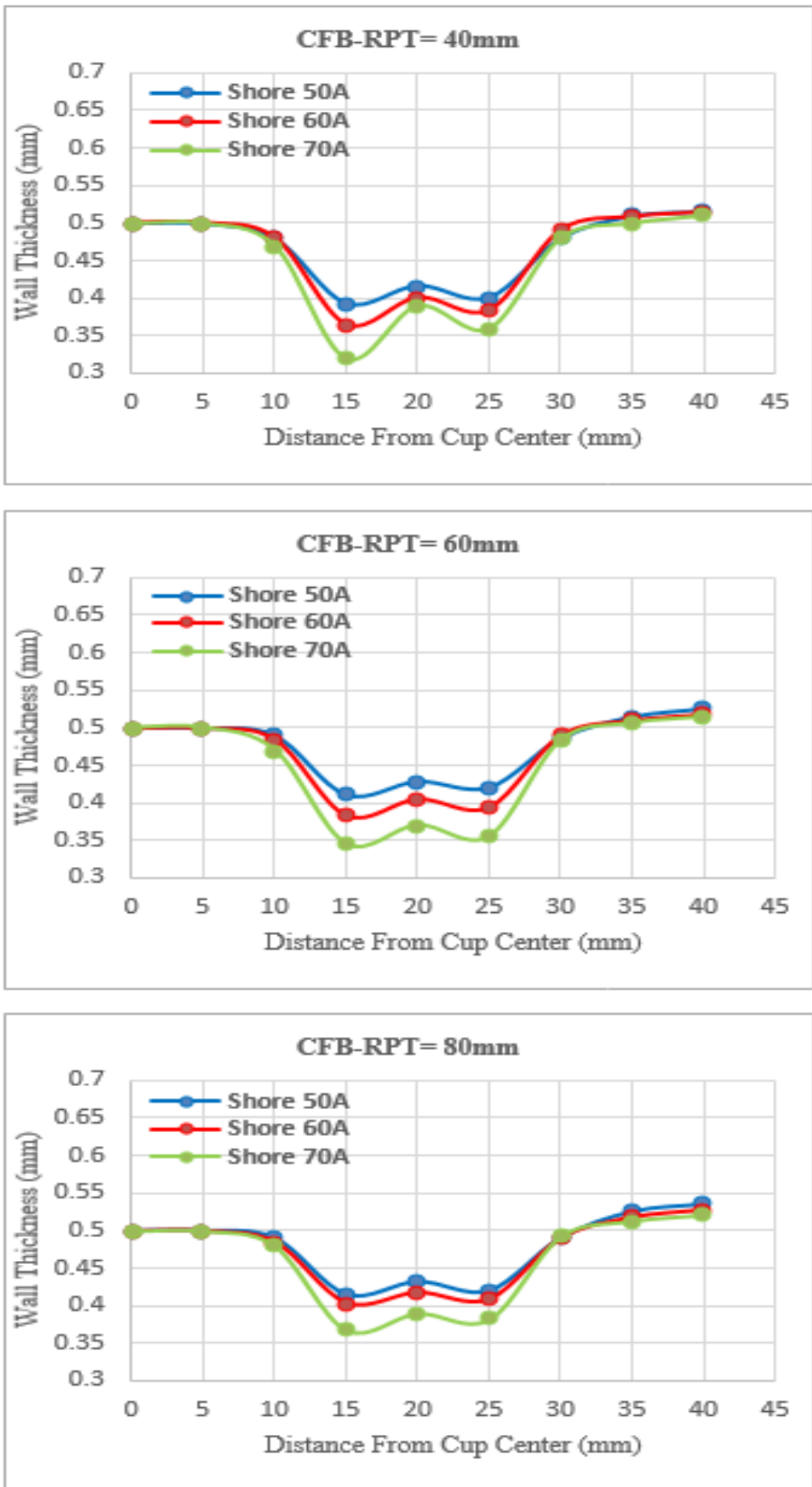

Figure (11). Numerical simulations models for a. flat b. hemispherical and c. complex former block. 


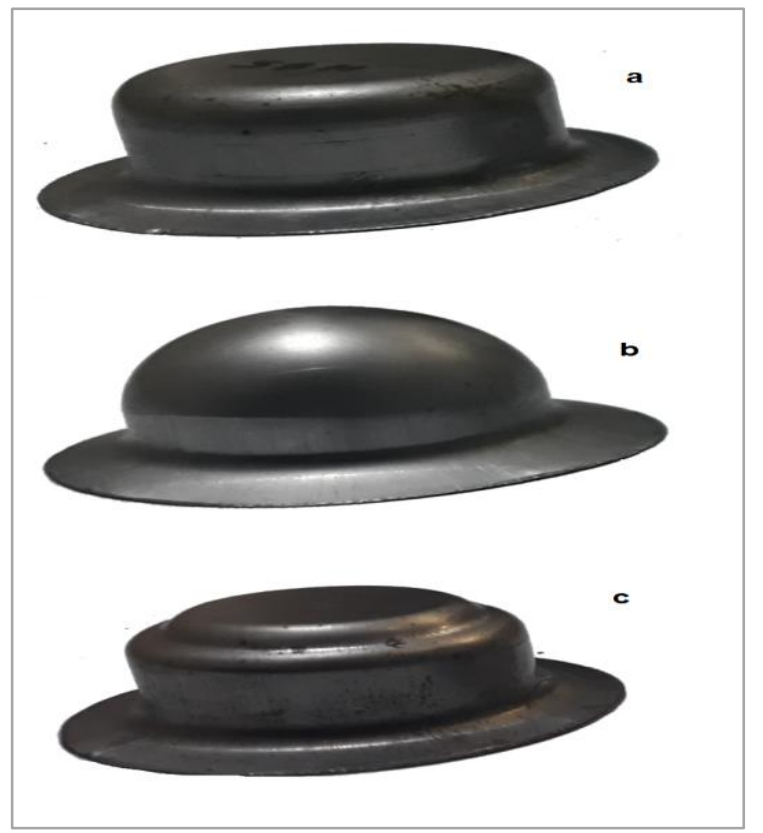

Figure 12. Samples of completely drawn cup of experimental work a. flat cup b.hemispherical cup c. complex cup.

\section{Conclusions}

1. This study has found that generally the thickness distribution improved by increasing RPT and decreasing RPH.

2. The results also presented that flat deformation styles presented best thickness distribution, while the worst was in complex deformation styles.

3. The results also obvious that flange thickening occurs with an increase in RPT.

\section{References}

[1] S.Thiruvarudchelvan "Elastomers in metal forming: A review" Journal of Materials Processing Technology, 39 55-82(1993).

[2] A. Rajab, I. Kader , A. Hammod "Mechanical properties (Tensile, Hardness and Shock resistance) for the phenol formaldehyde resin with Epoxy resin" Diyala Journal of Engineering Sciences Vol.12, No. 02, pages 35-43(2019).

[3] Saad Theeyab Faris "Analysis of plane strain rolling rigid plastic materials using finite element method" Diyala Journal of Engineering Sciences Vol.08, No. 02, pages 99-115(2015).

[4] M. Fu, H. Li, J.Lu, S.Lu, "Numerical study on the deformation behaviours of the flexible die forming by using viscoplastic pressure-carrying medium". Computational Materials Science 46 1058-1068 (2009).
[5] M. Ramezani, Z.Ripin, R. Ahmad "Computer aided modelling of friction in rubber-pad forming process" Journal of Materials Processing Technology 209 4925-4934 (2009).

[6] N. Abbas, R. Najmeh, J. Farideh, "Experimental investigation of Teflon-pad forming on circular metal blanks using a concave die," Journal of Manufacturing Process,20,282-90, (2015).

[7] M. Elyasi, F. Ahmadi Khatir, M. Hossein zadeh, "Manufacturing metallic bipolar plate fuel cells through rubber pad forming process," The International Journal of Advanced Manufacturing Technology, 1-13,(2016).

[8] Niknejad A and karami I "Teflon-pad shaping process of circular metal blanks into quasi- cup specimens by theoretical and experimental methods" Trans. Nonferrous Met. Soc. China (26) 213-227 (2016).

[9] Koubaa S, Belhassen L, Wali M and Dammak F "Numerical investigation of the forming apability of bulge process by using rubber as a forming medium" Int. J. Adv. Manuf. Technol. s00170-017-02781(2017).

[10] M. Tandogan, O. Eyercioglu "Hardness effect of polyurethane rubber on mesoscale rubber pad forming" International Advanced Research Journal in Science, Engineering and Technology, Vol.4, Issue 9, (2017).

[11] W. Hongyu, T. Fei, W. Zhen, Z. Pengchao, S. Juncai, J. Shijun "research about rubber pad forming of corner channel with convex or concave mould" Journal of manufacturing processes, 40, 94-104 (2019). 